Coastlines in plan. The arrival of the most persistent swell from a specific direction causes a net movement of sediment along the shore. It is important to know its direction in the design of maritime structures. A model study of the action of oblique swell on a straight sedimentary coastline with headlands, reported elsewhere ${ }^{4}$, indicated that half-hoartshaped bays were formed. The depth of indentation depends on the supply of material from upcoast, but for a condition of complete non-replenishment an equilibrium is reached for any given wave direction, in which event sediment movement ceases altogether. Examples from actual coastlines were cited in which a predominant swell direction was known to exist and where the bay formation was well developed.

The most efficacious location of groynes within such bays was diseussed. The uso of artificial headlands to stabilize coastal transport by promoting bay formation was submitted as a better solution than groynes, which in general influence only sand within the surf zone and are subject to rip formation.

Coastlines of the world. The half-heart shape of bay can be used as a tool to determine the direction of sediment movement on any coastline. This has been done by examination of Admiralty charts covering all oceans of the world and is reported elsewhere ${ }^{5}$. Where the equilibrium shape is not available other factors such as sand spits behind islands, as reported by Prof. Guilcher, ean be used. The final world-wide pattern of sedimont movement so obtained has correlated well with the wind systems of the globe. The work of J. L. Devies on similar lines ${ }^{6}$ was reported.

The meeting was convened in order to bring together research workers from various fields who wero interested in the particular study of sedimentary coastlines. It also served the purpose of indicating the different conditions experienced on coasts open to the ocean swell and thoso where the majority of the waves are generated locally. Emphasis was placed on wave action in the transport of material as distinct from tidal or other currents, which are of minor importance unless they are concentrated in narrow or shallow channels. R. SILvester

${ }^{1}$ Lonquet-Higgins, M. 8., Phil. Trans. Roy. Soc. (Lond.), A245, No. 903, 535 (1953).

2 Emery, K. O., and Foster, J. F., J. Mar. Res., "7, 644 (1948).

3 Grant, U. S., J. Mar. lies., 7, 655 (1948).

4 Silvester, R., Nature, 188, 467 (1960)

- Silvester, R., Proc. Conf. Inst. Civil Engin. Paper No. 14 (1962).

- Davies, J. I.., Z. Geomorphol. (in the press).

\title{
COMPARATIVE ENDOCRINOLOGY IN EUROPE
}

A CONFERENCE of European Comparative Endocrinologists was held in London in the rooms of the Zoological Society, by courtosy of the Council of the Society, during Septomber 19-21, and was attended by about 100 representatives of twelve countries. It was opened by Prof. G. J. van Oordt, who had been invited, on the occasion of his retirement from his chair of gonoral zoology and endocrinology in the University of Utrecht, to review aspects of European comparative endocrinology with which he and his colleagues had been closely connected.

Ho chose to deal particularly with developments in the field of sexual endocrinology, a subject which he introduced forty years ago into the biological laboratories of the Netherlands. The far-reaching influence that he has exerted through his own investigations, as well as through those of his pupils, was clearly brought out by the varioty of topics on which ho was able to touch, the major ones including the control of the reproductive processos of fishes and birds, and the factors influencing spermiation in amphibians. In declaring the Conference open, he expressed his confidence in the bright future of comparative endocrinological studies in Furope, and this optimism was cortainly justified by the interest and variety of the forty-eight papers which made up the rest of the scientific programme. It must be sufficient here to mention the main trends that emerged, for his addross will be published in full, together with abstracts of the other communications, in the current volume of General and Comparative Endocrinology.

A welcome feature was the prominence of invertebrate endocrinology, which was the subject of fourteen of the papers, for thero is sometimes a tendency for such conferences to concentrate on the higher vertebrates, and thereby to lose the great advantage of observing the working out of common principles in widely different groups of the animal kingdom. Studies of insects were naturally conspicuous here, and the widening range of application of ondocrino- logical principles was seon in an account of the role of sex ectohormones (pheromones) in the termite superorganism, the analysis of which can be pursued by methods fully analogous with those used in endocrine studies within the bodies of individual animals.

The control of colour change in crustaceans and the growth and moulting of both insects and crustaceans were discussed by several speakers, and it was gratifying to find that the endocrinological basis of these latter processes is now being studied in the difficult but important group of mites. The increasing attention that is being attracted by the lower invortebrates was also apparent, for several papers dealt with the annelid worms, with particular reference to the influence of neurosecretory centres on their reproduc. tion and life-cycles, including the induction and inhibition of the heteronereid phase.

The pituitary gland inevitably predominated in several sessions, in one or other of its many functional aspects. Prof. van Oordt's address was followed by several papers dealing with the control of colour change in Amphibia, and the younger workers present may well have been encouragod to find how vigor. ously rosearch and controversy are still being maintained in a subject that has for so long been a classical field of comparative vertobrate endocrinology. The pars distalis and its hormones also received attention, and papers on both electron microscopy and the more traditional polychromatic staining methods showed that while the complexity of this region is in full accord with the known variety of its functions, wo are still in no position to systematize our knowlodge of its histological differentiation.

The neurohypophysial hormones were dealt with by a numbor of workers, and rightly so, for in fow fields has the application of the comparative method yielded more stimulating results in recent years. Problems of the phyletic distribution of these hormones and of their modes of action were prominent. 
in these papers, and attention was also given to the fine structure of the hypothalamic neurosecretory cells from which they arise. The modes of action of hormones received further attention in other contexts also, the relationships between hormones and the metabolism and structure of their target cells being the theme of several papers, particularly with reference to thyroxine and the adrenocortical hormones. The sex hormones, prolactin, and the parathyroid gland were examined from the point of view of their influence on metabolism and differentiation in fishes, birds and mammals, while discussion of the function of melatonin, and of the histophysiology of the epiphysis, reminded the audience of familiar features of vertebrate organization that are only now beginning to receive searching analysis.

Time had been set aside at the end of the Conference dinner to enable members to discuss whether or not similar meetings should be planned in the future; but in the event this proved to be largely unnecessary, for it was made apparent throughout the three days that, despite the continued growth and proliferation of conferences and reunions, this meeting had met a real need. Partly this was so because representatives from many countries had been able to meet together at relatively small cost, but another reason was that this particular gathering had been planned to give younger workers the opportunity to report concisely on investigations that were still in progress, and to exchange ideas with those working on related problems in other laboratories. A contributory factor, too, was the congenial environment provided in the Zoological Society's rooms, and at Beit Hall (Imperial College of Science and Technology) and Bentham Hall (University College, London), for this made it possible to provide ample opportunity for informal discussion throughout the period of the meeting.

As a result, the participants came rapidly and unanimously to the view that they wished to have more of such conferences, and an invitation from Madame Herlant-Meewis to meet next autumn in Brussels was accepted with acclamation. The Brussels reunion, the second Conference of European Comparative Endocrinologists, will be held during September 16-18, 1963. Further announcements relating to it will appear in due course in General and Comparative Endocrinology, which will also publish its proceedings in abstract form.

\section{E. J. W. Barrington}

\section{EDUCATION AND TRAINING IN NUTRITION}

$\mathrm{T}$ is becoming increasingly recognized that the provision of food adequate both in quantity and in nutrient composition will not automatically abolish hunger and malnutrition. A book, published in connexion with the Freedom from Hunger Campaign *, is based on the thesis that it is "ignorance of the relationship between food and health" which would remain as the major bar to good nutrition. The book develops this thesis in a most readable and orderly way. It begins by giving several examples of the ways in which ignorance or misinformation can lead to malnutrition, even when nutritious foods are available. One is the practice in Indonesia where some of the children suffering from protein deficiency are not allowed to eat dried fish, because it is believed to cause worms. A second is the tendency for people moving from the countryside into the towns to buy new foods with low nutritional value because they are easy to prepare, or because they are considered to be "prestige foods".

That increased knowledge of nutrition may improve nutritional health is shown by several examples. Only one of these, in Israel, has, however, been adequately evaluated in terms of better dietary patterns in the families of those children who took part in a co-ordinated plan. In this, the children themselves were involved in growing foods in school gardens and in cooking and serving meals, as well as receiving instruction in food values.

This book is an excellent brief account of the whole problem of nutrition education for the people, of the training of professional nutritionists, and of the need to include study of the social aspects of nutrition as well as the physiological. However, one is a little sceptical of the belief on which the book is founded, that nutritional knowledge in itself is an assurance of sound nutritional habits where food supplies are

* FFHC Basic Study No. 6: Education and Training in Nutrition. Pp. vi 56. (Rome: Food and Agriculture Organization of the United Nations; London: H.M.S.O., 1962.) 2s. $6 d$. ; 50 cents. adequate. A recent survey in Britain has shown that most people believe that sugar is bad for teeth and that brown bread is more nutritious than white. This does not prevent the enormous consumption in Britain of sugar, nor does it stop people eating far more white bread than brown.

There is a still a widespread belief that people can get used to poor diets without any great impairment of health or of working efficiency. Nutrition and Working Efficiency $\dagger$ makes it quite clear that the chief reason for apparent lethargy and sluggishness of the inhabitants of many tropical countries is not laziness or racial characteristics or an enviable philosophy of life, but undernutrition and malnutrition. It cites many examples of the relationship between work output and adequate availability of food, and points out that improved nutrition can, in many parts of the world, break the vicious circle of poor nutritionphysical inefficiency-low food production-poor nutrition. The need is mostly for calories, but there is often a need also for more protein and vitamins. Moreover, heavy muscular exertion, needing increased muscular development and training, may itself require increased protein supplies, so that increased calories alone may not result in improved working efficiency in those who have lived much of their lives on inadequate diets.

The main purpose of this book is to direct the atten. tion of international and national agencies and private employers to the improvements which can be obtained through improved nutrition, and to outline the measures by which these can be achieved. These include stores where cheap food is available and subsidized food canteens, and provision should be made for the families as well as the workers. Through the stores and the canteens, the opportunity should be taken also to improve food habits and nutrition education. JOHN YUDKIN

$\uparrow$ FFHC Basic Study No. 5: Nutrition and Working Efficiency. Pp. 47. (Rome: Food and Agriculture Organization of the Unite 